\title{
PENGARUH RASIO-RASIO KEUANGAN TERHADAP PERUBAHAN LABA DAN CASH FLOW PADA PERUSAHAAN MANUFAKTUR YANG TERDAFTAR DI BURSA EFEK INDONESIA PADA TAHUN 2014-2016
}

\author{
Fidyah Arini Kusuma Wardhani \\ Sekolah Tinggi Ilmu Ekonomi Gempol \\ fidyaharini@gmail.com
}

\begin{abstract}
ABSTRAK
Penelitian ini dilakukan untuk meguji pengaruh rasio - rasio keuangan yang diproksikan dengan Current Ratio (CR), Debt Equity Ratio (DER), Total Asset Turnover (TAT), Return on Equity (ROE), dan Net Profit Margin (NPM) terhadap perubahan laba dan cash flow pada Perusahaan Manufaktur Yang Terdaftar Di Bursa Efek Indonesia Pada Tahun 2014-2016.Data diperoleh dengan metode purposive sampling dengan kriteria (1) Perusahaan yang tergolong ke dalam kelompok manufaktur yang melaporkan laporan keuangan secara konsisten dari tahun 2014-2016 di Bursa Efek Indonesia (2) Perusahaan telah mempublikasikan laporan keuangan per 31 Desember selama periode penelitian yaitu 2014-2016. (3) Memiliki Laba dan Cash Flow positif selama periode penelitian. (4) Laporan Keuangan yang dipublikasi menggunakan mata uang Rupiah. (5) Memiliki data laporan keuangan lengkap selama periode penelitian yaitu periode 2014-2016. Hasil Penelitian menunjukkan bahwa bahwa data yang ada terdistribusi normal, tidak terdapat multikolinieritas, tidak ada autokorelasi dan heteroskedasitas . Rasio keuangan yang diproksikan dengan DER berpengaruh signifikan terhadap perubahan laba dengan signifikansi p sebesar 0,011 dan ROE berpengaruh signifikan terhadap perubahan cash flow signifikansi p sebesar 0,030.
\end{abstract}

Kata Kunci : Current Ratio (CR), Debt Equity Ratio (DER), Total Asset Turnover (TAT), Return on Equity (ROE), Net Profit Margin (NPM), perubahan Laba, Perubahan cash flow

\section{PENDAHULUAN}

Motivasi Penelitian berdasarkan Penelitian dari Hapsari (2007) yang meneliti tentang "Analisis Rasio Untuk Memprediksi Pertumbuhan Laba Dengan Studi Kasus Perusahaan Manufaktur Yang Terdaftar Di Bursa Efek Jakarta Periode 2001 Sampai Dengan 2005". Hasil analisis regresi menunjukan bahwa Total Asset Turnover (TAT). Net Profit Margin
(NPM) dan Gross Profit Margin (GPM) berpengaruh positif dan signifikan terhadap pertumbuhan laba. Working Capital to Total Asset (WCTA), Current Liabilities To Inventory (CLI) dan Operating Income to Total Assets (OITL) tidak berpengaruh signifikan terhadap pertumbuhan laba.

Peneliti juga termotivasi dengan penelitian yang dilakukan Finger (1994) yang meneliti tentang "Kemampuan 
Laba Untuk Memprediksi Laba Dan Cash Flow Masa Depan”. Penelitiannya membahas tentang kemampuan laba untuk memprediksi laba dan cash flow di masa mendatang dan hasil analisis diperoleh bahwa CF lebih baik dibandigkan laba dalam memprediksi dengan masa prediksi relatif pendek (satu sampai dua tahun), tetapi laba dan CF memiliki kemampuan prediksi yang sama untuk jangka waktu yang lebih panjang.

Berdasarkan peneliti-peneliti terdahulu, peneliti tertarik untuk mengembangkan penelitian dari Hapsari (2007) dengan menambahkan variabel Cash Flow yang berpedoman pada penelitian Finger (1994). Berdasarkan penelitian tersebut, Peneliti menggunakan beberapa variabel mewakili rasio-rasio keuangan yang menjadi dasar para investor maupun kreditur atau stakeholder terhadap perubahan laba dan Cash Flow. Variabel yang di gunakan untuk mengukur pengaruh perubahan laba dan cash flow diantaranya Current Ratio (CR), Debt Equity Ratio (DER), Total Asset Turnover (TAT), Net Profit Margin (NPM) dan Return on Equity (ROE).

\section{TINJAUAN PUSTAKA}

\subsection{Perubahan Laba}

Belkaoui (1993) mengemukakan bahwa laba merupakan suatu pos dasar dan penting dari ikhtisar keuangan yang memiliki berbagai kegunaan dalam berbagai konteks. Laba umumnya dipandang sebagai suatu dasar bagi perpajakan, determinan pada kebijakan pembayaran dividen, pedoman investasi dan pengambilan keputusan dan unsur prediksi. Laba sebagai suatu alat prediktif yang membantu dalam peramalan laba mendatang dan peristiwa ekonomi yang akan datang. Nilai laba di masa lalu, yang didasarkan pada biaya historis dan nilai berjalan, terbukti berguna dalam meramalkan nilai mendatang.

Laba terdiri dari hasil opersional atau laba biasa dan hasil-hasil nonoperasional atau keuntungan dan kerugian luar biasa di mana jumlah keseluruhannya sama dengan laba bersih. Laba bisa dipandang sebagai suatu ukuran efisiensi. Laba adalah suatu ukuran kepengurusan (stewardship) manajemen atas sumberdaya suatu kesatuan dan ukuran efisiensi manajemen dalam menjalankan usaha suatu perusahaan (Belkaoui, 1993). 


\subsection{Perubahan Cash Flow}

Pandangan Takhtaei dan Karimi (2013), arus kas yang memberikan gambaran tentang keadaan operasional perusahaan memiliki kemampuan dalam memprediksi arus kas masa depan. Prediksi arus kas membantu investor dalam melihat kinerja operasional perusahaan dalam jangka pendek maupun panjang.

Arus kas dapat digunakan sebagai Menentukan tingkat kebutuhan perusahaan untuk memegang atau menahan uang dalam bentuk kas untuk mempertahankan kontinuitas operasi perusahaan. Sikap perusahaan terhadap pembagian deviden atau penanaman kembali keuntungan didalam perusahaan dalam bentuk investasi dan sebagainya.

Jumlah arus kas yang berasal dari aktivitas operasi merupakan indikator yang menentukan apakah dari operasinya perusahaan dapat menghasilkan arus kas yang cukup untuk melunasi pinjaman, memelihara kemampuan operasi perusahaan, membayar dividen dan melakukan investasi baru tanpa mengandalkan pada sumber pendanaan dari luar. Informasi mengenai unsur tertentu arus kas historis bersama dengan informasi lain berguna dalam memprediksi arus kas operasi masa depan.

\subsection{Rasio Keuangan}

Rasio Keuangan adalah membandingkan angka-angka yang ada dalam laporan keuangan dengan cara membagi satu angka dengan angka lainnya. perbandingan dapat dilakukan antara satu komponen dengan kemponen dalam satu laporan keuangan atau antar komponen yang ada di antara laporan keuangan. Kemudian angka yang diperbandingkan dapat berupa angkaangka dalam satu periode maupun beberapa periode (Wibowo, 2011).

Menurut Brigham dkk (2003), dari sudut pandang seorang investor, meramalkan masa depan adalah hakikat dari analisis laporan keuangan akan bermanfaat baik untuk membantu mengantisipasi kondisi-kondisi dimasa depan maupun yang lebih penting lagi, sebagai titik awal melakukan perencanaan langkah-langkah yang akan meningkatkan kinerja perusahaan di masa depan.

Rasio menggambarkan suatu hubungan atau perimbangan (mathematical relationship) antara suatu jumlah tertentu dengan jumlah yang lain, dan dengan menggunakan alat analisa 
berupa rasio ini akan dapat menjelaskan atau memberi gambaran kepada penganalisa tentang baik atau buruknya keadaan atau posisi keuangan suatu perusahaan (Hapsari,2007).

Penelitian ini menggunakan rasiorasio keuangan sebagai berikut:

\section{a. Rasio likuiditas diproksikan dengan Current Ratio (CR).}

CR yang tinggi menunjukkan adanya kelebihan aktiva lancar sehingga laba bersih yang dihasilkan semakin sedikit dibandingkan dengan kelebihan aktiva tetap. CR dirumuskan sebagai berikut yaitu :

$$
C R=\frac{\text { Current Assaet }}{\text { Current Liabilities }}
$$

\section{b. Rasio Solvabilitas diproksikan dengan Debt to Equity Ratio (DER).} Jumlah hutang semakin besar dibandingkan dengan keseluruhan modal sendiri yang dimiliki, berarti risiko bagi investor semakin tinggi (Syamsudin, 2009). Rumus DER sebagai berikut :

$$
D E R=\frac{\text { Total Debt }}{\text { Total Equity }}
$$

\section{c. Rasio Aktivitas diproksikan \\ dengan Total Assat Turnover (TAT).}

Rasio yang menggambarkan bagaimana efektifitas perusahaan menggunakan keseluruhan aktiva untuk menciptakan penjualan dan laba (Syamsudin, 2009).

Perhitungan rasio ini adalah

$$
\mathrm{TAT}=\frac{\text { Penjualan }}{\text { Jumlah Aktiva }}
$$

\section{d. Rasio Profitabilitas Diproksikan Dengan Net Profit Margin (NPM) Dan Return On Equity (ROE).}

NPM digunakan dalam mengukur kemampuan perusahaan dalam menghasilkan laba kaitannya dengan penjualan yang dicapai (Syamsudin, 2009). Sedangkan ROE digunakan untuk mengukur profitabilitas dari perspektif pemegang saham biasa. Menunjukkan seberapa banyak rupiah yang diperoleh dari laba bersih untuk setiap rupiah yang diinvestasikan oleh para pemegang saham (Wibowo, 2011). NPM dan ROE dirumuskan sebagai berikut

$$
\begin{aligned}
\text { NPM } & =\frac{\text { Laba Bersih Setelah Pajak }}{\text { Penjualan Bersih }} \\
\text { ROE } & =\frac{\text { Laba Bersih Setelah Pajak }}{\text { Modal Sendiri }}
\end{aligned}
$$

\section{METODELOGI PENELITIAN}

Laba yang digunakan dalam penelitian ini adalah laba setelah pajak (Earning After Tax), dapat dirumuskan sebagai berikut (Hapsari, 2007)

$$
\Delta E_{i t}=\frac{\mathrm{E}_{\mathrm{it}}-\mathrm{E}_{\mathrm{it}-1}}{\mathrm{E}_{\mathrm{it}-1}}
$$

Prediksi CF dapat dirumuskan sebagai berikut (Ginting,2011) :

$$
\Delta C F_{i t}=\frac{\mathrm{CF}_{\mathrm{it}}-\mathrm{CF}_{\mathrm{it}-1}}{\mathrm{CF}_{\mathrm{it}-1}}
$$

\subsection{Model Penelititan}

\begin{tabular}{|l|l|}
\hline - CR (X1) \\
- DER (X2) \\
- TAT (X3) \\
- NPM (X4) \\
- ROE (X5)
\end{tabular}


Model dalam penelitian ini adalah :

$\mathrm{Y}_{1}=\mathrm{a}+\mathrm{b} 1 \mathrm{X} 1+\mathrm{b} 2 \mathrm{X} 2+\mathrm{b} 3 \mathrm{X} 3+\mathrm{b} 4 \mathrm{X} 4+$ $\mathrm{b} 5 \mathrm{X} 5+\mathrm{e}$

Dimana $\mathrm{Y}_{\mathrm{t}}=$ Perubahan laba

$\mathrm{a}=$ Koefisien konstanta

$b=$ Koefisien regresi dari masing-masing variabel

$\mathrm{X}_{1}=\mathrm{CR}$

$\mathrm{X}_{2}=\mathrm{DER}$

$\mathrm{X}_{3}=\mathrm{TAT}$

$\mathrm{X}_{4}=\mathrm{NPM}$

$\mathrm{X}_{5}=\mathrm{ROE}$

$\mathrm{Y}_{2}=\mathrm{a}+\mathrm{b} 1 \mathrm{X} 1+\mathrm{b} 2 \mathrm{X} 2+\mathrm{b} 3 \mathrm{X} 3+\mathrm{b} 4 \mathrm{X} 4+$ $\mathrm{b} 5 \mathrm{X} 5+\mathrm{e}$

Dimana $Y_{2}=$ Perubahan laba

$\mathrm{a}=$ Koefisien konstanta

$\mathrm{b}=$ Koefisien regresi dari masing-masing variabel

$\mathrm{X}_{1}=\mathrm{CR}$

$\mathrm{X}_{2}=\mathrm{DER}$

$\mathrm{X}_{3}=\mathrm{TAT}$

$\mathrm{X}_{4}=\mathrm{NPM}$

$\mathrm{X}_{5}=\mathrm{ROE}$

\subsection{Kerangka Konseptual}

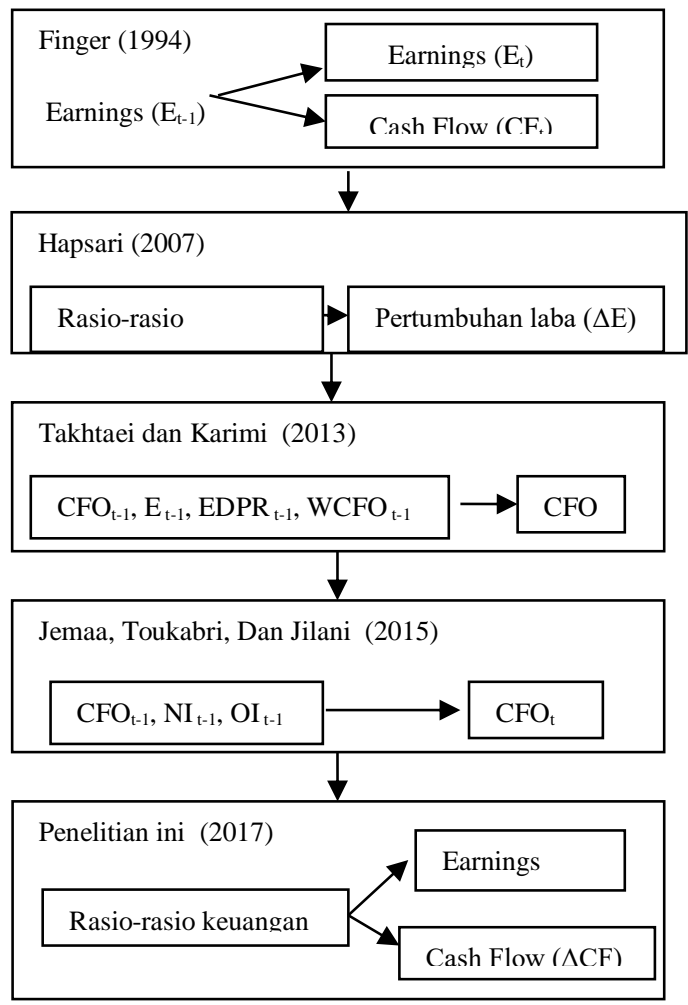

\subsection{Teknik Analisis}

Data penelitian dianalisis dengan menggunakan metode regresi berganda melalui program Statitical Package for Social Scienses (SPSS versi 16,0) dengan urutan sebagai berikut: Analisis Deskriptif, Uji Asumsi Klasik, Uji ketepatan model dan koefisien determian, Uji Signifikansi variabel.

\section{HASIL DAN PEMBAHASAN}

Penelitian ini menggunakan data sekunder dalam bentuk pooled cross sectional dengan periode 2014 sampai dengan 2016 dengan sampel sebanyak 41 Perusahaan manufaktur, maka secara pooled cross sectional diperoleh sejumlah 41 perusahaan $\times 3$ tahun $=123$ data obervasi. Data tersebut dilakukan perhitungan rata - rata (Average) sehingga menghasilkan 41 data observasi.

Variabel Independen yang digunakan dalam penelitian ini adalah CR, DER, TAT, ROE, NPM. Sedangkan variabel dependenya adalah prediksi laba dan prediksi cash flow.

\subsection{Uji Asumsi Klasik}

Uji Asumsi Klasik digunakan untuk menguji, apakah model regresi yang digunakan dalam penelitian ini layak diuji atau tidak. Uji Asumsi Klasik digunakan untuk memastikan bahwa multikolinearitas, autokorelasi, dan heteroskedastisitas tidak terdapat dalam model yang digunakan dan data yang dihasilkan terdistribusi normal. Jika keseluruhan syarat tersebut terpenuhi, berarti bahwa model analisis telah layak digunakan (Hapsari, 2007). 
Pengujian normalitas menggunakan uji Kolmogorov-Smirnov. Hasil uji normalitas menunjukkan bahwa semua variabel mencapai normal yang ditunjukkan dengan nilai signifikan > 0,05 .

Uji Multikolinearitas dilakukan untuk mengetahui apakah terdapat interkorelasi sempurna antar variabelvariabel independen yang digunakan dalam penelitian ini. Uji ini dilakukan dengan Tolerance Value dan Variance Inflation Factor (VIF). Agar tidak Multikolinearitas, batas Tolerance Value > 0,1 dan VIF < 10. Hasilnya terlihat untuk 5 variabel independen Tolerance Value lebih dari 0,1 dan angka VIF kurang dari 10, sehingga dapat disimpulkan bahwa kelima variabel independen tersebut tidak ada hubungan Multikolinearitas dan model regresi layak untuk digunakan.

Untuk mengetahui ada atau tidaknya autokorelasi dalam model regresi, dilakukan pengujian DurbinWatson (DW). hasil pengujian menunjukkan nilai DW 1,927 dengan Adjusted $R$ Square sebesar 0,268 untuk perubahan laba dan DW 1,882 dengan Adjusted R Square sebesar 0,212 untuk Perubahan cash flow. Berdasarkan hasil tersebut, nilai DW berada diantara -2 sampai 2, sehingga dapat disimpulkan bahwa tidak terdapat autokorelasi pada persamaan regresi penelitian ini.

Model penelitian yang baik adalah homoskeditas, yaitu varian dan residu satu pengamatan ke pengamatan yang lain hasilnya tetap. Terdapat beberapa cara dalam mendeteksi adanya heteroskeditas yang menunjukkan bahwa model penelitian kurang layak.
Dalam penelitian ini digunakan diagram titik (Scatterplot) yang seharusnya titikttik tersebut tersebar secara acak agar tidak terdapat heteroskeditas.

\subsection{Analisis Regresi Berganda}

Pengujian ini bertujuan untuk menganalisis apakah model dalam penelitian ini tepat atau tidak. Analisis regresi berganda digunakan untuk menguji model penelitian tentang pengaruh rasio-rasio keuangan terhadap prediksi laba dan cash flow. Berdasarkan analisis regresi berganda dapat diketahui bahwa model penelitian yang digunakan sudah tepat. Hal ini dapat dibuktikan dari nilai signifikan F kurang dari 0,05.

Koefisien determinasi $\left(\mathrm{R}^{2}\right)$ pada intinya mengukur seberapa jauh kemampuan model dalam menerangkan variabel dependen. Nilai $\mathrm{R}^{2}$ yang kecil berarti kemampuan variabel-variabel independen dalam menjelaskan variabel dependen, terbatas. Sebaliknya, nilai $\mathrm{R}^{2}$ yang mendekati satu menandakan variabel-variabel independen memberikan hampir semua informasi yang dibutuhkan oleh variabel dependen (Hapsari, 2007).

Berdasarkan hasil uji koefisien determinan tersebut menunjukan bahwa korelasi antara perubahan laba dengan seluruh variabel independen adalah kuat karena $\mathrm{R}$ sebesar 0,600 lebih dari 0,05 dengan nilai Adjusted $R$ Square sebesar 0,268 berarti $27 \%$ perubahan laba disebabkan oleh CR,DER,TAT,ROE, dan NPM. Korelasi antara perubahan cash flow dengan seluruh variabel independen adalah kuat karena $\mathrm{R}$ sebesar 0,557 lebih dari 0,05 dengan Adjusted $R$ Square sebesar 0,212 berarti $21 \%$ 
perubahan cash flow disebabkan oleh CR,DER,TAT,ROE, dan NPM.

Pengujian ini dilakukan untuk mengetahui apakah masing-masing variabel independen berpengaruh signifikan terhadap variabel dependen. Tingkat signifikan $(\alpha)$ sebesar 0,05 . Apabilai nilai signifikan $<0,05$ maka variabel intependen tersebut berpengaruh signifikan terhadap variabel dependen.

Berdasarkan hasil perhitungan hanya DER yang berpengaruh secara signifikan terhadap variabel dependen yaitu perubahan laba, dengan signifikansi p sebesar 0,011. Sedangkan keempat varibel independen yaitu CR,TAT, ROE, dan NPM tidak memiliki pengaruh signifikan terhadap prediksi laba. Hal ini dikarenakan nilai signifikansi keempat variabel masingmasing 0,$156 ; 0,197 ; 0,837$; dan 0,565, yang berarti lebih besar dari tingkat signifikansi sebesar 0,05. Dan hasil perhitungan diatas, hanya ROE yang berpengaruh secara signifikan terhadap variabel dependen yaitu perubahan cash flow, dengan signifikansi p sebesar 0,030. Sedangkan keempat varibel independen yaitu CR, DER, TAT, dan NPM tidak memiliki pengaruh signifikan terhadap perubahan cash flow. Hal ini dikarenakan nilai signifikansi keempat variabel masing-masing 0,235 ; 0,$458 ; 0,072$; dan 0,347 , yang berarti lebih besar dari tingkat signifikansi sebesar 0,05 .

\subsection{Simpulan dan keterbatasan Penelitian}

Rasio keuangan yang dianalisis dengan proksi DER berpengaruh signifikan terhadap perubahan laba, sedangkan rasio keuangan yang diproksikan dengan CR, TAT, ROE, dan NPM tidak berpengaruh signifikan terhadap perubahan laba. Hasil analisis ini menunjukkan bahwa semakin besar DER akan semakin meningkatkan perubahan laba, dimana semakin perusahaan memiliki hutang yang tinggi membuat perusahaan lebih berjuang guna meningkatkan laba untuk membayar hutang tersebut.

Rasio keuangan yang diproksikan dengan ROE berpengaruh signifikan terhadap Perubahan cash flow, dan keempat rasio yaitu CR, DER,TAT, dan NPM tidak berpengaruh terhadap perubahan cash flow. Hasil ini dimaksudkan bahwa semakin besar ROE maka semakin meningkat perubahan yang terjadi pada cash flow. ROE yang tinggi memberikan tingkat kepercayaan kepada investor terhadap kinerja perusahaan, sehingga para investor yakin bahwa cash flow aman dan dapat digunakan secara baik dan tidak ada kekosongan dalam cash flow.

Keterbatasan Penelitian ini hanya menggunakan 5 Rasio keuangan yang mewakili masing-masing rasio yaitu Rasio likuiditas, Solvabilitas, Aktifitas dan profitabilitas. Faktor - faktor diluar rasio keuangan tidak masuk dalam penelitian ini. Laba dan Cash flow yang dianalisis merupakan laba tahun ini bukan tahun yang akan datang.

Untuk peneliti selanjutnya, diharapkan menambah rasio keuangan agar lebih maksimal dalam memprediksi laba dan cash flow. Melakukan Uji Beda antara prediksi laba dengan prediksi cash flow. 


\section{DAFTAR PUSTAKA}

Amalina, Nur., Arifin Sabeni. 2014. Analisis Rasio Keuangan Dalam Memprediksi Perubahan Laba (Studi Empiris pada Perusahaan Manufaktur yang Terdaftar pada BEI periode tahun 2008-2011). Diponegoro Journal of Accounting. Vol. 3 No. 1 Tahun 2014 hal. 1-15.

Andini, Dessy Putri, 2010. Kemampuan Prediksi Rasio-Rasio Keuangan Terhadap Laba Dan Arus Kas Masa Depan Dan Pengaruhnya Terhadap Deviden Payout Ratio Pada Perusahaan Manufaktur Dan Jasa. Jounal Publikasi.

Baridwan, Zaki. 2005. Intermediate Accounting, Edisi 8. Penerbit BPFE UGM. Yogyakarta.

Belkaoui, Ahmed Riahi, 2007, Teori Akuntansi, Edisi Lima, Salemba Empat, Jakarta

Brigham, Eugene, F dan Michael C, Enhardt., 2003, Financial Management Theory and Practice 11th Edition, Thomson and SouthWestern

Finger, Catherine A., 1994. The Ability of Earning to predict Future Earning and Cash Flow. Journal of Accounting Research. Vol. 32 No. 2 (Autumn, 1994), pp 210-223.

Fakultas Ekonomi, 2012. Modul Aplikasi Komputer Manajemen. Universitas Wijaya Kusuma Surabaya.

Gani, Engelwati, Almitra Indira. 2011. Analisa Rasio Keuangan Untuk Memprediksi Perubahan Laba
Pada Peusahaan Telekomunikasi Indonesia. Binus Business review. Vol.2 No.2 hal. 883-898.

Ghozali, Imam, 2011, Aplikasi Analisis Multivariate dengan Program SPSS, Badan Penerbit Universitas Diponegoro, Semarang

Gustina, Dhany Lia, Andhi W. 2015.Analisis Rasaio Keuangan Dalam Memprediksi Perubahan Laba. Manajement Analysis Journal 4 (2).

Hapsari, Epri A.,2007. Analisa Rasio Keuangan Untik Memprediksi Pertumbuhan Laba (Studi Kasus Perusahaan Manufaktur yang Terdaftar di BEJ periode 2001 sampai dengan 2005). Tesis Undip. Dipublikasi.

Joni, 2011. Daya Prediksi Laba dan Aliran Kas (Studi Empiris pada Perusahaan Manufaktur di Bursa Efek Indonesia Periode 20052009). Jurnal Riview Akuntansi dan Keuangan. Vol. 1 No. 1 April 2011.

Jemaa, Olfa B., Mohamed Toukabri, Faouzi Jilani, 2015. The Examination of The Ability of Earnings and Cash Flow in Predicting Future Cash Flows : Application to the Tunisian Context. Accounting and Finance Research. Vol. 4 No. 1

Munawir, S, 2007, Analisa Laporan Keuangan, Liberty, Yogyakarta

Riyanto, Bambang, 1995, Dasar-dasar Pembelanjaan Perusahaan Edisi 4, BPFE, Yogyakarta 
Sujarweni, V.Wiratna, 2016. Kupas

Tuntas Penelitian Akuntansi dengan SPSS Edisi Lengkap. Pustaka Baru Press, Yogyakarta.

Suwarno, Agus H., 2004. Manfaat Informasi Rasio Keuangan dalam Prediksi Perubahan Laba (Studi Empiris Terhadap Perusahaan Manufaktur Go Publik di Bursa Efek Jakarta). Tesis Undip Dipublikasikan

Syamsudin, Ceky Primayuta. 2009. Rasio Keuangan dan Prediksi Perubahan Laba Perusahaan Manufaktur yang Terdaftar di Bursa Efek Indonesia. BENEFIT Jurnal Manajemen dan Bisnis Volume 13, No.1 Juni 2009, Hlm 61-69.

Takhtaei, Nasrollah., Hassan Karimi, 2013. Relative Ability of Earning Data and Cash Flow in Predicting Future Cash Flows. International Journal of Accounting and Financial Reporting. Vol. 3 No. 1

Usman, Bahtiar, 2003, “Analisis Rasio Keuangan dalam Memprediksi Perubahan Laba pada Bank-Bank di Indonesia”, Media Riset Bisnis \& Manajemen, Vol 3 No.

Wibowo, Hendra A., Diyah Pujiati. 2011. Analisis Rasio Keuangan Dalam Memprediksi Perubahan Laba Pada Perusahaan Real Estate dan Property di Bursa Efek Indonesia (BEI) dan Singapura (SGX). The Indonesian Accounting Review. Volume 1, No. 2, July 2011, pages $155-178$

Wild, John J., K.R. Subramanyam, Robert F. Halsey. 2009. Financial Statement Analisis., 10 th edition. 
